\title{
Simple Synthesis Route to Monodispersed SBA-15 Silica Rods
}

\author{
Abdelhamid SAYARI ${ }^{*}$, Bao-Hang HAN, and Yong YANG
}

Centre for Catalysis Research and Innovation (CCRI), Department of Chemistry University of Ottawa, Ottawa, Ontario, Canada K1N 6N5

\section{Supporting Information}
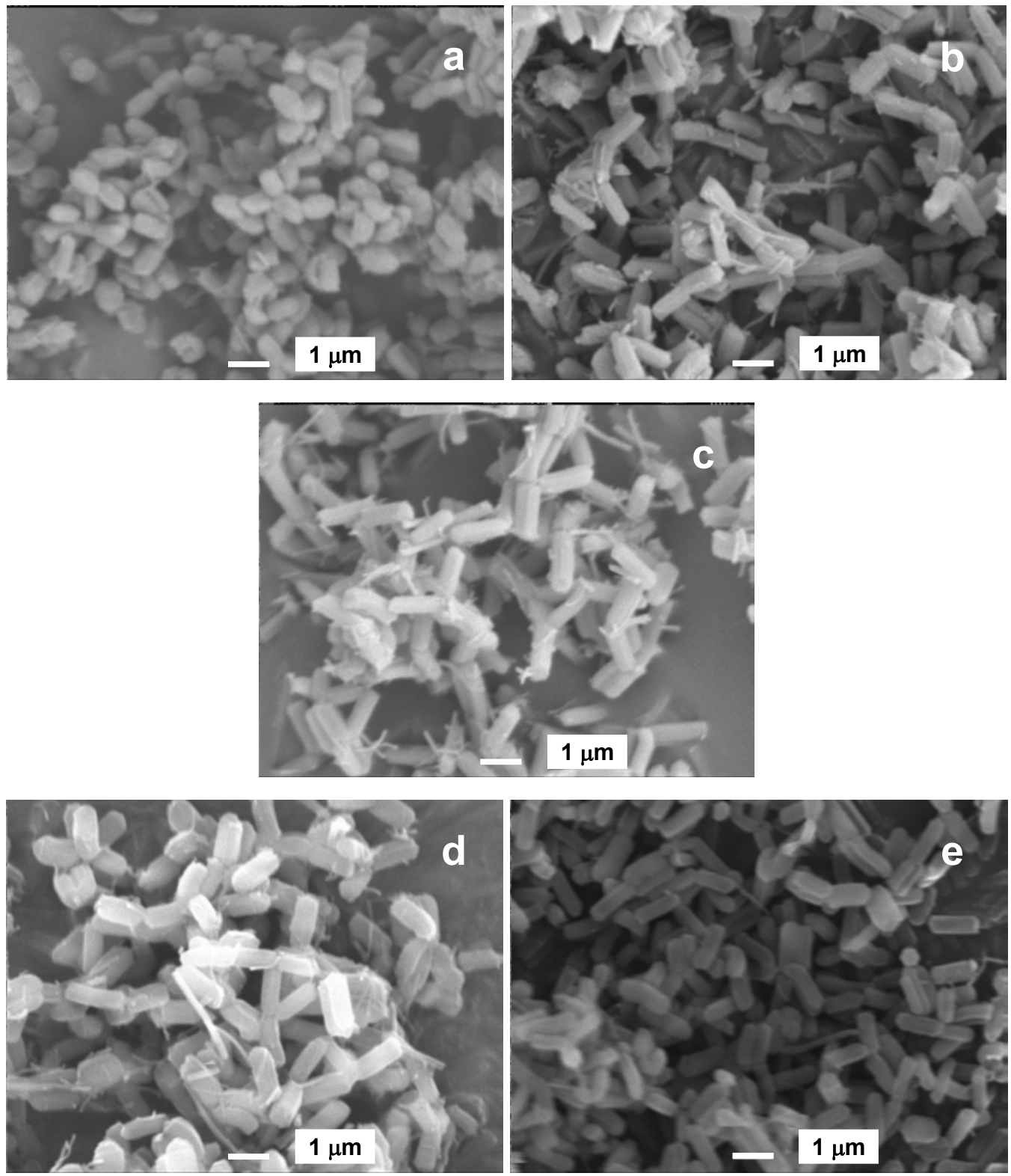

Figure S-1. SEM images of SBA-15 samples prepared under static conditions at (a) $35^{\circ} \mathrm{C}$, (b) $60{ }^{\circ} \mathrm{C}$, (c) $80^{\circ} \mathrm{C}$, (d) $100^{\circ} \mathrm{C}$, (e) $130{ }^{\circ} \mathrm{C}$.

In addition to the rod-like particles, thinner fibers comprised of a limited number of silica tubes are observed. These offshoots have the same length as the rod-like particles. 

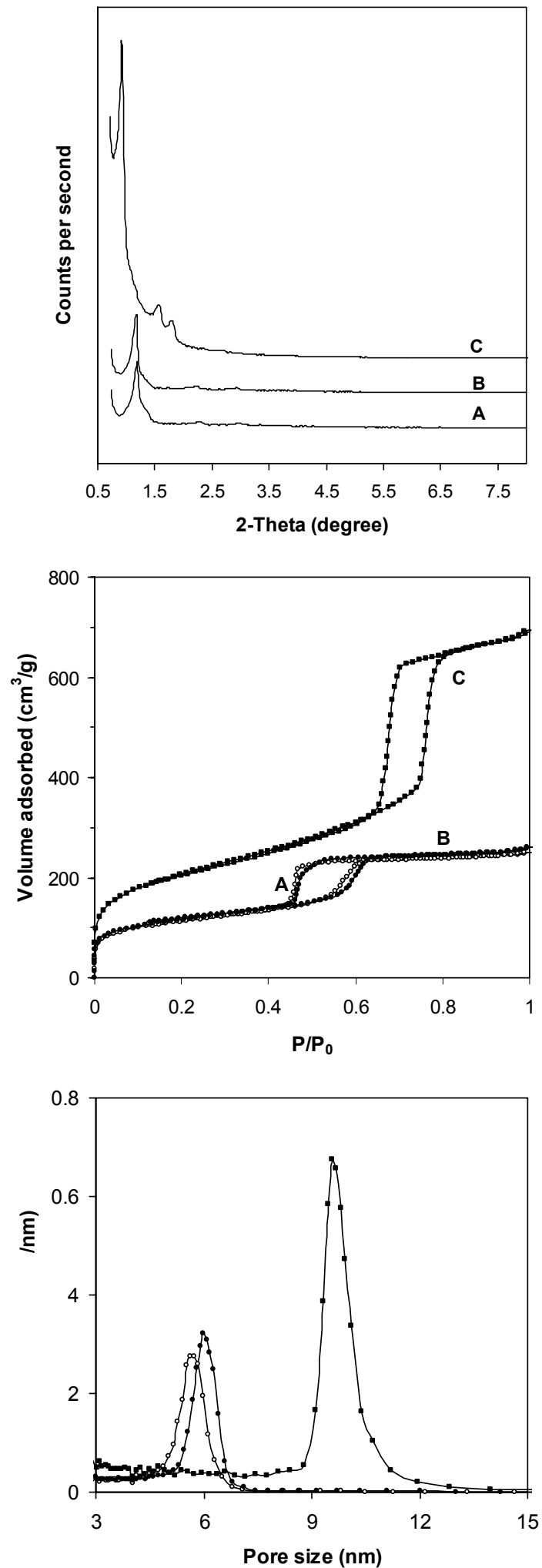

Figure S-2. XRD patterns, nitrogen adsorptiondesorption isotherms, and pore size distributions for (A) sample prepared in a single step without stirring at $35^{\circ} \mathrm{C}$ for $6 \mathrm{~h}$, (B) sample prepared as sample A, but for $24 \mathrm{~h}$; (C) sample B heated further at $100^{\circ} \mathrm{C}$ for $24 \mathrm{~h}$.
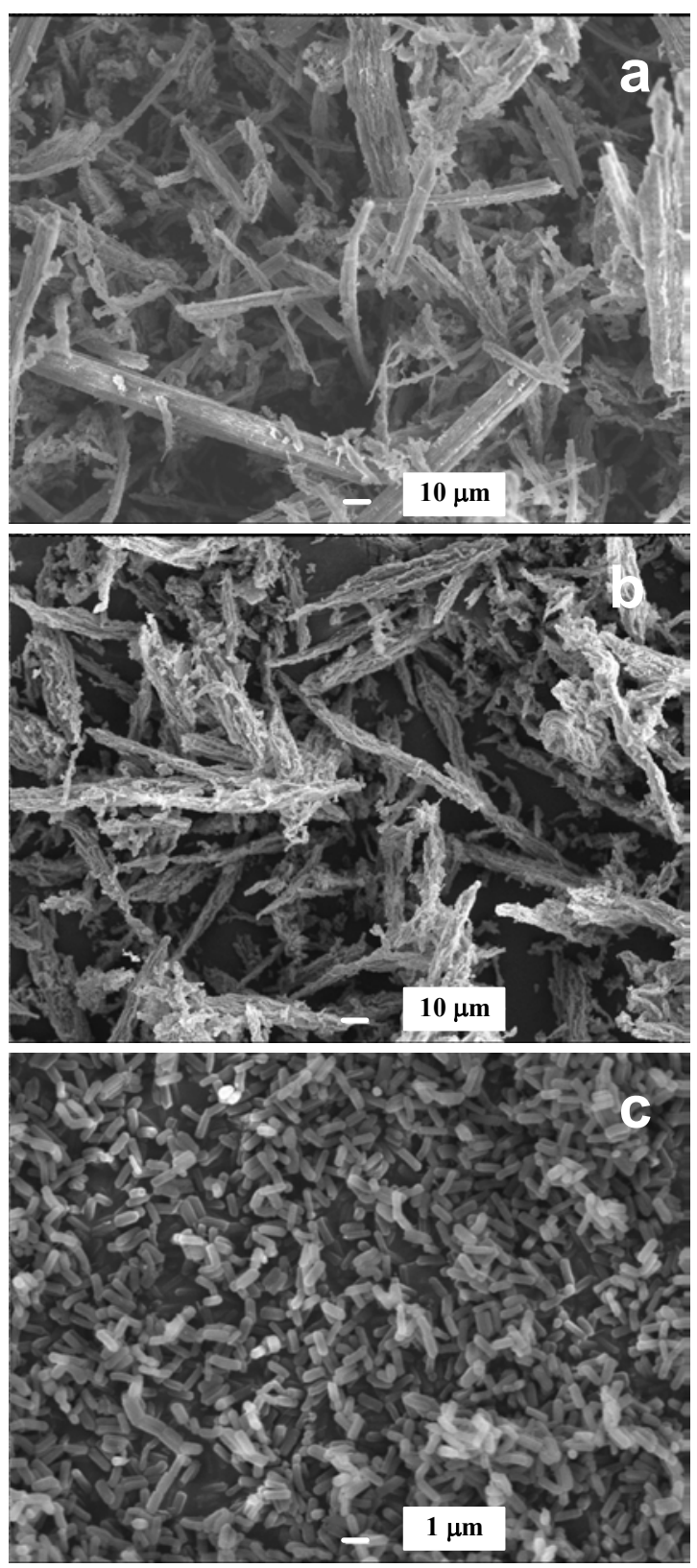

Figure S-3. SEM images of SBA-15 samples prepared at $130{ }^{\circ} \mathrm{C}(\mathrm{a})$ with stirring in the absence of salt, (b) with stirring in the presence of $\mathrm{NaCl}(\mathrm{NaCl} / \mathrm{SiO} 2=0.5)$, and (c) without stirring in the absence of salt. 